\title{
EUTOMIA
}

Revista de Literatura e Linguística

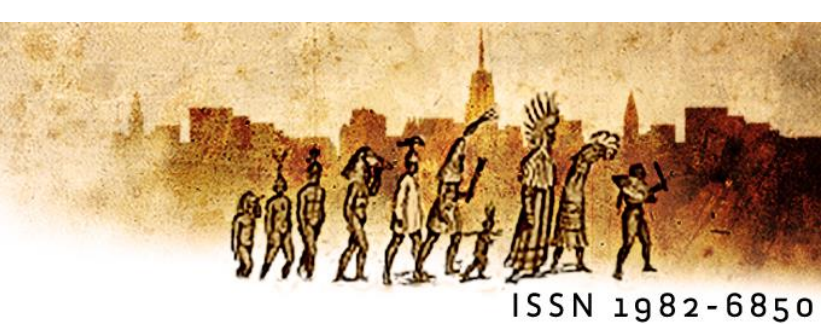

\section{A pesquisa como dispositivo de desenvolvimento profissional de professores}

\section{Research as professional development device for teachers}

\author{
Gabriela Lins Falcãoi (IFPE) \\ Lívia Suassunaii (UFPE)
}

\begin{abstract}
Resumo: Os atuais dispositivos norteadores da formação dos docentes, bem como as pesquisas desenvolvidas nesse campo no Brasil e ao redor do mundo, definem a atividade de pesquisa como parte fundamental da formação e da atuação de professores, nas diferentes etapas da educação. A produção científica sobre esse tema, em particular, aponta que não é apenas como processo cognitivo que a pesquisa pode contribuir para o desenvolvimento profissional, haja vista seu potencial para a construção e a aquisição de novos saberes por parte do pesquisador, mas também como prática social. Baseados nesse entendimento e à luz da concepção de pesquisa descrita no continuum defendido por Beillerot (2001), discutimos, neste estudo, de natureza qualitativa, as contribuições da pesquisa para desenvolvimento profissional do professor de português na educação básica, a partir de autores como André (2001), Lüdke (2001), Diniz-Pereira e Zeichner (2011), Pimenta (2012) e Tardif e Moscoso (2018) e de dados produzidos por meio da aplicação de questionário e entrevista semiestruturada junto a nove docentes de uma unidade da Rede Federal de Educação Profissional, Científica e Tecnológica. Os resultados da investigação ratificam a importância da pesquisa como princípio formativo e como prática profissional de professores da educação básica.

Palavras-chave: Desenvolvimento profissional; formação de professores; pesquisa docente; professor de português
\end{abstract}

La recherche comme outil de développement professionnel pour les enseignants

Résumé : Les dispositifs d'orientation actuels de la formation des enseignants, ainsi que les recherches développées dans ce domaine au Brésil et dans le monde, définissent l'activité de recherche comme un élément fondamental de la formation et des performances des enseignants aux différentes étapes de l'éducation. La production scientifique sur ce sujet, en particulier, souligne que ce n'est pas seulement en tant que processus cognitif que la recherche peut contribuer au développement professionnel, compte tenu de son potentiel de construction et d'acquisition de nouvelles connaissances par le chercheur, mais aussi en tant que pratique social. Sur la base de cette compréhension et à la lumière du concept de recherche décrit dans le continuum défendu par Beillerot (2001), nous discutons, dans cette étude de nature qualitative, les apports de

Eutomia, Recife, 27(1): 121-142, Out. 2020 
la recherche au développement professionnel de l'enseignant de portugais en éducation de base, basé sur des auteurs comme André (2001), Lüdke (2001), Diniz-Pereira e Zeichner (2011), Pimenta (2012) e Tardif e Moscoso (2018) et à partir des données issues de la réalisation d'un questionnaire et d'un entretien semi-structuré avec neuf enseignants d'une unité du Réseau fédéral de l'enseignement professionnel, scientifique et technologique brésilien. Les résultats de l'enquête confirment l'importance de la recherche comme principe formateur et comme pratique professionnelle de la première étape de l'éducation.

Mots clés: Développement professionnel; formation des enseignants; recherche comme pratique professionelle; enseignant de portugais.

\section{Introdução}

O presente estudo originou-se do nosso interesse de conhecer e discutir o trabalho do professor de português da educação básica no que diz respeito a sua prática de pesquisa nesse contexto. As produções acadêmicas da área da formação de professores e do ensino de língua portuguesa, bem como as novas Diretrizes Curriculares Nacionais para a formação inicial em nível superior (cursos de licenciatura, cursos de formação pedagógica para graduados e cursos de segunda licenciatura) e para a formação continuada assumem a relevância das práticas investigativas para a formação e a atuação docentes. No entanto, estudos recentes apontam entraves, oriundos, especialmente, de aspectos relacionados às trajetórias formativas e às condições de trabalho desses profissionais, como dificultadores da concretização dessas práticas nas diferentes etapas da educação básica brasileira (KLEIMAN, 2001; ANDRÉ, 2001; LÜDKE, 2001; DINIZ-PEREIRA, 2011; FALCÃO, 2013; TARDIF; MOSCOSO, 2018).

Os diferentes momentos que compõem a história da formação docente no Brasil e suas múltiplas descontinuidades, sobretudo no tocante à existência de um modelo formativo baseado em conteúdos acadêmico-científicos, e a importância, por vezes ignorada, de sua relação com a formação específica/didático-pedagógica permitem-nos entender os processos e as concepções de educação vigentes, e perceber que, muitas vezes, estes se apresentam distantes das funções e necessidades concretas da profissão. Ao entendermos a escola, como assume Dayrell (1996), como espaço sociocultural e heterogêneo, compreendemo-la, também, como ambiente potencialmente capaz de produzir e de reformular conhecimentos.

Concordamos com Demo (1990) quando este afirma que: 
a primeira preocupação é repensar o "professor" e na verdade recriá-lo. De mero "ensinador" - instrutor no sentido mais barato - deve passar a "mestre". Para tanto, é essencial recuperar a atitude de pesquisa, assumindo-a como conduta estrutural, a começar pelo reconhecimento de que sem ela não há como ser professor em sentido pleno. (DEMO, 1990, p. 32).

Diante da construção histórica dessa conjuntura e das tensões que cercam as concepções de formação e as atribuições dos educadores em nosso país, consideramos pertinente o que diz Santos (2001) quanto à necessidade de buscar uma formação que lhes permita assumir sua identidade como trabalhadores culturais envolvidos na produção de uma memória histórica e de sujeitos sociais que possam criar e recriar o espaço e a vida sociais. Assim, tanto a formação inicial quanto a formação continuada de professores, em disciplinas gerais ou específicas, devem contribuir para um preparo coerente com os ideais que reafirmam a identidade e a autonomia como necessárias aos docentes no exercício de sua profissão, bem como uma postura docente crítico-reflexiva e em constante (re)construção a partir dos diversos saberes que a constituem (CONTRERAS, 2002; PIMENTA, 2012).

A importância da adoção de uma postura investigativa pelo docente reside, portanto, na possibilidade que esta tem de contribuir também para o surgimento de um olhar crítico e reflexivo sobre a prática docente, não de forma massiva, inconteste ou absolutizante, mas na perspectiva da reformulação de conhecimentos teóricometodológicos, por exemplo, acerca das práticas educativas e dos objetos de ensino. Tratase de um princípio pedagógico essencial, conforme definem as Diretrizes Curriculares Nacionais para a formação inicial em nível superior (cursos de licenciatura, cursos de formação pedagógica para graduados e cursos de segunda licenciatura) e para a formação continuada (BRASIL, 2015).

A partir dessa perspectiva teórica - que encara a pesquisa como ação rigorosa e processual, possível de ser realizada no ambiente escolar e necessária à atividade docente, porquanto capaz de colaborar para o seu enriquecimento - é que a presente pesquisa foi desenvolvida. Tal perspectiva também é assumida por Schnetzler (1998), que reforça a necessidade de a pesquisa educacional ser considerada constitutiva das próprias atividades docentes, "condição de desenvolvimento profissional do professor e de melhoria da sua 
prática pedagógica" (p. 8). Dessa forma, o trabalho com pesquisa é aqui considerado como importante mecanismo para alcançar uma prática docente crítico-reflexiva e distanciada de uma postura meramente técnica e reprodutora.

Diante das múltiplas possibilidades de categorização e da inexistência de modelos que discutam e classifiquem mais claramente as investigações desenvolvidas por professores da educação básica, aderimos ao que foi proposto por Beillerot (2001) e consideramos a cientificidade, a produção de novos saberes, o rigor metodológico e a divulgação de resultados como bases fundamentais para definir o que estamos entendendo por pesquisa.

Ademais, o trabalho investigativo é aqui considerado como importante mecanismo para criar um "espaço de resistência, de crédito e de mérito" para os professores desde a educação básica (SCHNETZLER, 1998, p. 8), que inclui - embora ultrapasse - os limites de seu objeto específico de ensino.

\section{Caracterização dos procedimentos metodológicos, do lócus e dos sujeitos de pesquisa}

Considerando as (inter)relações entre sujeitos e práticas no ambiente escolar, e as particularidades da construção desse cotidiano, a presente pesquisa foi desenvolvida com base no paradigma qualitativo, utilizando-se o questionário e a entrevista semiestruturada como instrumentos principais para a produção dos dados. Por meio da análise documental, constituímos um corpus secundário, que contribuiu para a caracterização do campo e dos sujeitos pesquisados, bem como das pesquisas por eles desenvolvidas.

A partir das análises decorrentes das 28 perguntas de nosso questionário, ampliadas e aprofundadas por meio de entrevista individual, obtivemos dados acerca das práticas investigativas desenvolvidas pelos professores pesquisadores ao longo de suas trajetórias formativas e profissionais, bem como das possíveis influências destas no entendimento dos objetos e objetivos de ensino, informações que oportunizaram, ainda, a produção de um panorama das vivências investigativas desses sujeitos e das transformações à prática escolar e pedagógica decorrentes do contato com os processos de construção do conhecimento.

Por compreendermos que as práticas de pesquisa exigem grande comprometimento do pesquisador e que, quando do exercício da profissão docente, tais práticas estão 
condicionadas também à formação e às condições de trabalho (DINIZ-PEREIRA, 2011; FALCÃO, 2013), escolhemos o Instituto Federal de Educação, Ciência e Tecnologia de Pernambuco (IFPE), pertencente à Rede Federal de Educação Profissional, Científica e Tecnológica, como campo de estudo. Tal escolha justifica-se pela organização institucional do trabalho docente - baseada na tríade ensino-pesquisa-extensão -, pela existência de programas internos de fomento à pesquisa, bem como pelos valores e políticas adotados nas instituições da citada Rede em relação a seu quadro de servidores, que congrega mestres e doutores em atuação também na educação básica.

Além de regulamentada no âmbito da Rede Federal de Educação Profissional, Científica e Tecnológica pela Lei n 11.892/2008 (BRASIL, 2008), a atividade investigativa como missão no interior dos Institutos Federais é reafirmada a partir de ações específicas, como o estímulo à criação e ao registro de grupos de pesquisa, o lançamento de editais de fomento, a organização de eventos para socialização das investigações realizadas no âmbito da Rede, entre outras.

Segundo dados obtidos junto ao IFPE, no ano de 2019, cerca de 54 cursos atendiam a uma média de 17.500 mil estudantes em diferentes níveis e modalidades de formação: ensino médio, técnico, superior, além de especialização e mestrado. A instituição é atualmente constituída por um Campus Virtual da Educação a Distância (EaD), com aulas presenciais em 19 polos, e por 16 campi, estes últimos com sede física em distintas mesorregiões do estado.

Participaram do nosso estudo nove docentes, selecionados a partir de informações obtidas: 1) do cadastro de pesquisadores da Pró-Reitoria de Pesquisa e Inovação da instituição; 2) do Catálogo de Grupos de Pesquisa da instituição e 3) dos resultados dos dois últimos editais anuais do Programa de Iniciação Científica e Tecnológica (PIBIC TÉCNICO). Utilizamos ainda, para a escolha desses profissionais, os seguintes critérios: 1) ser docente de língua portuguesa em atuação nos cursos da Educação Profissional Técnica de Nível Médio; 2) ter projeto(s) de pesquisa, na área de linguagem, cadastrado(s) na Pró-Reitoria de Pesquisa do IFPE e/ou em agências de fomento; 3) ser mestre ou doutor por programas de pós-graduação relacionados à área de linguagem e/ou de ensino; 4) ter contrato de dedicação exclusiva que tornasse a atividade investigativa parte de suas atribuições na instituição. 
Todos os informantes do estudo vivenciaram experiências de pesquisas anteriores a seu ingresso no IFPE, seja durante a formação inicial, em projetos de iniciação científica, seja em processos de formação continuada, considerando os cursos de mestrado e/ou doutorado já concluídos. Selecionamos, portanto, sujeitos familiarizados com o desenvolvimento de práticas investigativas, considerando as habilidades teóricometodológicas necessárias e as especificidades do fazer científico (BEILLEROT, 2001; FARE; CARVALHO; PEREIRA, 2017).

\section{Identidade docente e construção de redes colaborativas: a formação para, com e pela pesquisa}

Dandurand e Olivier (1993) afirmam que "os fatores que trazem as capacidades de produção, de difusão e de apropriação dos conhecimentos e dos saberes se tornaram centrais tanto para os indivíduos, como para os grupos de toda natureza" (p. 385). Nessa perspectiva, é imperioso que os docentes em atuação na educação básica possam se apropriar dos instrumentos de produção, de apropriação crítica e reformulação de saberes e conhecimentos, ligados, estes, ao próprio processo contínuo e inacabado de conscientização e de problematização do saber e do fazer docente.

Reconhecemos, na fala de nossos sujeitos, a existência do impacto formativo das práticas investigativas desde a formação inicial, mas também, de forma continuada, por meio da participação em cursos de pós-graduação stricto sensu, bem como dos próprios projetos que tais profissionais puderam desenvolver já durante a atuação profissional, portanto, sem a colaboração direta de orientador(es) e/ou de outras instituições formadoras e com temáticas construídas para além, o que não significa dizer dissociadas, da realidade vivenciada em sala de aula.

Essa trajetória de pesquisa fez com que, dos nove professores que responderam a nosso questionário, seis assumissem plenamente a identidade de professor pesquisador e apenas três o fizessem de forma parcial. Todos os informantes, portanto, consideram-se professores pesquisadores, e os três que reconheceram que o são parcialmente se justificaram, aludindo a eventuais excessos de carga horária destinada a atividades de ensino, circunstância que os impede de se dedicar às experiências de pesquisa da forma como gostariam.

Tal relação fica ainda mais evidenciada ao afirmarem, todos os nove sujeitos, que Eutomia, Recife, 27(1): 121-142, Out. 2020 
consideram produzir ou terem produzido conhecimento ao longo de suas trajetórias, e que sua formação - tanto inicial quanto continuada - ofereceu os saberes necessários para que desenvolvessem pesquisa em sua profissão. Sobre a identidade como professora pesquisadora, a docente $\mathrm{R}_{1}{ }^{1}$ diz na entrevista:

Toda a minha formação desde a graduação até agora foi pontuada pela pesquisa. E agora no IF, que a gente tem um espaço de trabalhar em ensino, pesquisa e extensão, já continua (...). Eu respondi no questionário "sim", porque fez parte da minha formação na graduação em licenciatura e fez parte do, em paralelo, meu trabalho em sala de aula. Quando eu estava em sala de aula, eu estava pesquisando de alguma forma, também, fora. E aqui no IF pesquisando dentro. Teve a parte do doutorado, mas eu concluí o projeto de PIBIC num ano e... Estou agora engatando o pós-doutorado. Sempre a pesquisa me acompanhou nessa trajetória. [R1]

A justificativa para o reconhecimento de sua identidade de professora pesquisadora, na fala de $R_{1}$, encontra-se presente na maioria dos registros dos demais entrevistados, e decorre das experiências que muitos desses docentes tiveram com as práticas investigativas desde a formação inicial, atreladas à possibilidade de continuidade desse envolvimento a partir da situação que vivenciam no IFPE, inclusive com participação em grupos de pesquisa e orientação de estudantes.

Para muitos desses sujeitos, a atividade de pesquisa tornou-se indissociável da função docente, corroborando o que afirmam autores como Lüdke e Cruz (2005), ao discutirem os saberes elaborados pelos docentes e a importância da construção de conhecimento por parte desses profissionais, "pela proximidade com a realidade da sala de aula e em função de seu próprio desenvolvimento profissional" (LÜDKE; CRUZ, 2005, p.87). Vejamos algumas falas nesse sentido:

Eu não sei fazer uma coisa sem outra (...), é por isso que eu formalizei [a pesquisa] mesmo porque as coisas surgem, né, dentro da sala de aula, e a gente quer dar continuidade e às vezes a pesquisa vai da sala de aula para o pesquisador para o momento da pesquisa ou às vezes é o contrário, vai da pesquisa para a sala de aula. E eu acho que é sempre assim. [R3]

Eu acho possível e, inclusive, necessário [que o professor da educação básica seja também pesquisador]. Eu acho fundamental. Eu tenho dificuldade, na

\footnotetext{
1 A fim de preservar a identidade dos docentes colaboradores da pesquisa, utilizamos, para citá-los, uma codificação composta por uma letra e um número, em que a letra representa o campus onde cada um atua e o número foi atribuído em sequência, conforme o quantitativo de informantes da unidade em questão.
}

Eutomia, Recife, 27(1): 121-142, Out. 2020 
verdade, de conceber a ideia do professor que não é pesquisador, mas, claro que, para isso, é necessário uma série de investimentos (...). [C1]

À luz de autores como Freire (1987) e Tardif (2011), os quais ressaltam a importância de entender os contextos sociais e profissionais em que se constroem as experiências e as identidades docentes, concebemos a pesquisa não como mais uma atribuição a ser sobreposta às atividades docentes, trazendo sobrecarga ao trabalho dos professores em atuação na educação básica de nosso país, mas como instrumento de formação e de valorização do docente enquanto produtor de conhecimento.

Todos os posicionamentos acima transcritos foram proferidos por docentes que tiveram suas primeiras experiências com pesquisa científica ainda durante a formação inicial, no curso de Letras, em instituições universitárias. Dos nove docentes informantes deste estudo, cinco disseram ter tido experiências de iniciação científica durante a graduação, algumas, inclusive, custeadas por meio de bolsas concedidas por agências de fomento.

Para Soares (2001), a formação do "professor investigador" deve ser produto da vivência do licenciando, desde o início de sua trajetória na universidade, da pesquisa como processo, o que faz com que o futuro professor não só aprenda, mas também apreenda o processo de investigação, incorporando a "postura de investigador" em seu trabalho cotidiano na escola e na sala de aula. Não afirmamos que tal postura ou identidade como pesquisador advenha automaticamente do contato com as práticas investigativas no interior das licenciaturas, mas ratificamos a relevância dessa aproximação como parte importante na formação docente, com possíveis impactos na atuação, especialmente em sua dimensão propedêutica, objetivando conferir a esse profissional familiaridade com práticas a serem desenvolvidas em futuras experiências profissionais e formativas (FALCÃO, 2013).

Com o propósito de situarmos o período e as condições da formação inicial vivenciada pelo grupo de docentes, pontuamos que, dos nove professores que responderam a nosso questionário, sete são oriundos de instituições universitárias públicas federais ou estaduais, e apenas duas se formaram em instituições particulares. Uma dessas duas professoras, inclusive, é a única formada há mais de 20 anos, e, quando perguntada sobre se 
se considera produtora de conhecimento, fez as seguintes ressalvas acerca de sua trajetória formativa:

A pesquisa começou para mim muito tardia, porque eu venho de uma faculdade particular e aí eu só entrei para a universidade pública quando fiz o mestrado e o doutorado. Então, não tive esse processo inicial que é muito comum o aluno ter na graduação... essa experiência. Ainda teve o fato de acumular exatamente dois empregos e estudar à noite, não é? [R5]

As ressalvas presentes na fala da professora $\mathrm{R}_{5}$ dizem respeito ao fato de sua formação inicial ter ocorrido em instituição de ensino superior privada e de natureza não universitária, e, portanto, fora da tríade ensino, pesquisa e extensão, e também às dificuldades enfrentadas por ser estudante em turno noturno e com tempo reduzido, devido à inserção antecipada no mercado de trabalho. Outro destaque que fazemos, em relação a seu perfil, é o tempo de conclusão de sua graduação, realizada, diferentemente do caso dos demais informantes deste estudo, há mais de 20 anos, ou seja, dentro de um contexto em que ainda era incipiente o desenvolvimento de pesquisas científicas pelos alunos no âmbito da formação inicial em licenciatura.

Lüdke (2001) e Lüdke, Rodrigues e Portella (2012) demonstram o papel fundamental dos cursos de pós-graduação na formação do professor para a pesquisa. Apontam os cursos stricto sensu como sendo, majoritariamente, o primeiro contato com a pesquisa para muitos docentes em atuação. Para esses autores, as condições históricas de desenvolvimento da pesquisa científica no Brasil, de forma mais sistemática, ligam-se aos programas de pósgraduação das universidades e às suas fontes de fomento.

A formação do pesquisador na pós-graduação stricto sensu é resultado, segundo Fare, Carvalho e Pereira (2017), da convergência de um amplo conjunto de relações e espaços formais, conjunto esse que conduz a uma ideia de transmissão do ofício de cientista, envolvendo hábitos científicos ou um modus operandi científico, como denominou Bourdieu (2005). É, portanto, aos cursos de pós-graduação stricto sensu que normalmente se atribuem as responsabilidades de formar e de requerer atividades de pesquisa dos docentes em atuação na educação básica.

Esse cenário remete ao que foi constatado na pesquisa de mestrado de uma das autoras deste artigo, realizada com docentes lotados em Escolas de Referência da Rede Pública Estadual de Pernambuco (FALCÃO, 2013). No referido estudo, pudemos comprovar 
o papel da pós-graduação stricto sensu na formação dos professores como pesquisadores, especialmente no tocante à aproximação desses profissionais com os processos forjadores do conhecimento, impactando a forma, inclusive, como estes se relacionam com os objetos de ensino. Diferentemente do que ocorre nas escolas do Estado de Pernambuco, no entanto, a maioria dos professores do IFPE apresentou experiência e familiaridade com a pesquisa já desde a sua formação inicial, o que contribuiu para a construção e o reconhecimento mais precoce dessa identidade de professor pesquisador.

Ainda sobre a participação em cursos de pós-graduação, apenas um docente, dentre os noves participantes da pesquisa, não possuía doutorado, tendo titulação de mestre. Outra informante, $\mathrm{R}_{5}$, inclusive, mesmo classificando o início de sua formação para pesquisa como tardio, tendo em vista a inexistência de tal experiência na graduação, já possuía o título de doutorado. Além disso, do total de oito doutores deste estudo, dois fizeram pós-doutorado, com liberação e apoio financeiro do IFPE.

Na medida em que apontavam, em entrevista, os aspectos formativos reconhecidamente presentes nas práticas de pesquisa desenvolvidas por eles ao longo de suas trajetórias docentes, os professores elencavam algumas das ações e vivências próprias do universo acadêmico-científico, como as leituras necessárias ao desenvolvimento da fundamentação teórica de seus estudos. Uma vez que a pesquisa é parte do trabalho e da carga horária semanal docente, havendo, inclusive, momentos de trocas e partilhas com orientandos e a formação de grupos ou núcleos de pesquisa, as leituras e a busca teórica integram esses afazeres "cotidianos", oportunizando a atualização a partir do contato permanente com teorias, produções científicas e autores relacionados às temáticas pesquisadas. É o que se pode verificar no depoimento de $\mathrm{R}_{3}$ :

A pesquisa, ela me obriga a estudar, mesmo que eu não quisesse! Tenho tempo não, porque eu tenho que preparar aula, tenho que preparar slide, eu tenho que corrigir prova, eu tenho que elaborar prova... mas eu estou pesquisando, minha filha, então eu vou ter que parar para ler para poder discutir com minhas orientandas, então, a pesquisa ela me obriga a parar. $A$ parar e a ler, acho que isso me ajuda na formação e isso interfere no ensino (...). $\left[R_{3}\right]$

Todos os docentes apontaram o acesso a textos acadêmico-científicos como "ganho" (termo usado por R4) advindo do fato de serem professores que pesquisam, visto que permite "renovar as abordagens e os conhecimentos" (R1), "manter-se atualizado na Eutomia, Recife, 27(1): 121-142, Out. 2020 
sua área ou em áreas correlatas" (R6), além do aprofundamento sistemático nos diferentes objetos estudados. Segundo R4, a pesquisa permite que o professor e o ensino avancem, "que se libertem de falsos ou ultrapassados conceitos, que não se sustentam mais cientificamente".

Tal afirmação converge com a defesa de Dornelles (2007) no tocante à necessária apropriação, por parte dos docentes, das diferentes conceituações do conhecimento, do estudo científico da linguagem e dos metadiscursos sobre a língua, a fim de buscarem as reestruturações que se fazem necessárias no processo de ensino-aprendizagem de língua portuguesa. Tal achado aponta caminhos, portanto, para o entendimento da atualização, e da possibilidade de protagonismo desses profissionais frente ao "discurso da mudança" no ensino de português (DE PIETRI, 2003).

Afirmamos isso por termos em conta que os estudos acerca do ensino de português no Brasil tornaram-se mais recorrentes a partir da década de 1980 e trouxeram reflexões fundamentais - tanto do ponto de vista epistemológico, quando do pedagógico e do sociopolítico - para o desenvolvimento de algumas mudanças nos objetos e objetivos das aulas de língua materna (ANTUNES, 2007; SOARES, 2002; SUASSUNA, 2006). Segundo De Pietri (2003) e Dornelles (2007), tal discurso da mudança é protagonizado pela ciência linguística, campo determinante no projeto oficial de inovação no ensino de língua portuguesa.

Altman (1998), ao realizar uma historiografia da produção linguística brasileira do período compreendido entre 1968 e 1988, mostra, por sua vez, como a virada pragmática e o surgimento da Linguística como disciplina autônoma provocaram mudanças relacionadas tanto aos modos de produção de conhecimento sobre a linguagem, quanto com relação à organização acadêmica e profissional. No tocante à educação básica, tal impacto permitiu desencadear alterações significativas, por exemplo, quanto à concepção de língua, trazendo o texto, em sua pluridimensionalidade, a atividade linguística e os elementos enunciativos para o centro do processo de ensino-aprendizagem, em uma visão integrada e ampliada dos mecanismos de produção e de interação por meio da linguagem.

Sabemos da inexistência de uma relação direta entre atualização teórica e práticas inovadoras, e também não acreditamos na superioridade da teoria em relação a outras esferas e domínios relacionados ao fazer docente, tendo em vista a complexidade do 
trabalho e dos saberes desses profissionais (TARDIF; LESSARD; GAUTHIER, 2001; TARDIF, 2011), mas concordamos com Cadilhe e Garcia-Reis (2017), quando, ao discorrerem acerca dos letramentos na formação de professores a partir de uma concepção discursiva da linguagem, afirmam que, "para que uma mudança de perspectiva se efetive nas práticas didático-metodológicas em sala de aula, no planejamento do professor e em sua atuação profissional, será preciso uma compreensão dessa abordagem" (p. 216).

Esses autores ajudaram-nos a olhar para os conceitos-chave e as tendências investigativas presentes nos projetos de pesquisa de nossos professores pesquisadores (os quais compuseram o corpus secundário deste estudo), e reconhecer as contribuições não apenas quanto a procedimentos, sistematizações e análises dispostos em suas propostas e projetos, mas também quanto à fundamentação e ao aprofundamento teórico no campo da linguística e das práticas discursivas de linguagem como possíveis contributos das práticas investigativas para a sua formação.

Considerando as discussões provenientes da busca por uma prática docente reflexiva - buscando situá-la em termos de uma compreensão histórica, social, política e transformadora desses profissionais, condizentes com uma perspectiva crítico-reflexiva (CONTRERAS, 2002) -, destacamos aqui também a fala de Imbernón (2016) acerca da relevância do progressivo domínio da teoria como parte da formação docente:

a teoria ajuda a repensar a prática, a compartilhar dúvidas e problemas. A teoria ajuda a desenvolver capacidades reflexivas, uma das habilidades imprescindiveis na profissão docente. Ajuda a saber por que as coisas são feitas e a considerar questões e capacidades reflexivas imprescindíveis no campo da educação. Ajuda a aumentar a consciência de que ensinar e aprender é complexo [...] (IMBERNÓN, 2016, p. 125).

Se, para o autor, o "professor não deve refletir unicamente sobre sua prática, mas sua reflexão atravessa as paredes da instituição para analisar todo tipo de interesses subjacentes à educação" (IMBERNÓN, 2016, p. 42), registramos, ainda, dadas as condições de trabalho no interior do espaço escolar e a trajetória formativa desses profissionais em atuação na Rede Federal de Educação Profissional, Científica e Tecnológica, a possibilidade de que a pesquisa também cumpra esse papel formativo para o professor, ao favorecer a compreensão, a sistematização crítica e a produção de conhecimentos sobre a educação, o 
seu fazer pedagógico e, em termos epistemológicos, os conceitos e as temáticas referentes ao objeto de ensino e seu processo de ensino-aprendizagem.

Outra oportunidade formativa reconhecidamente atrelada à prática de pesquisador por nossos entrevistados decorre da possibilidade de uma maior partilha e integração com outros profissionais. A participação em eventos, como ouvintes ou com apresentação dos produtos de suas pesquisas, foi constantemente relatada, bem como a participação em grupos de pesquisa, no interior do IFPE ou em ações interinstitucionais, que também incluem as universidades, e constituem, para esses professores, diferenciais em suas trajetórias profissionais, por favorecerem momentos em que, como professores pesquisadores, estão num duplo processo de socialização e de formação.

Fazer pesquisa dá acesso a outros espaços de construção de saber... é fundamental você estar ouvindo palestras, você estar ouvindo pesquisas que estão sendo realizadas, né? Travando discussões, apresentando seu trabalho, porque quando a gente leva um trabalho de pesquisa para apresentar, a gente fala sobre o que a gente está fazendo, sobre o que a gente está investigando... [R3]

Esta semana mesmo eu estava no GEL... a gente está sempre pensando... teve a semana Nacional de Ciência e Tecnologia; teve um evento que a gente organizou lá no âmbito da nossa coordenação no primeiro semestre, então a gente tá sempre buscando essa discussão, esses espaços, e geralmente isso acontece a partir da pesquisa (...). O ato de pesquisar é um processo de formação contínua, ele faz com que a formação não fique, muitas vezes [restrita] à pós-graduação, a um novo curso... pesquisar também é formar o profissional, o professor. [R2]

Sobre esse tema, destacamos a oportunidade, percebida como valorosa por nossos sujeitos, no tocante à interação e à colaboração com outros profissionais. Interagir e aprender com os pares pode se constituir em experiências significativas para o professor, possibilitando a reafirmação de um paradigma que entenda a profissão e o trabalho docente, e até mesmo seus processos formativos, a partir de perspectivas colaborativas.

Charlot (2012) chama atenção para o problema decorrente da ausência de apropriação, por parte da maioria dos professores em atuação na educação básica, de categorias para discutir e dizer o seu trabalho. Para o autor, "o pesquisador, no decorrer de sua vida intelectual, no ambiente de discussão com outros pesquisadores, está desenvolvendo uma teoria. O professor, através das categorias que usa para dizer a sua 
prática, também está desenvolvendo uma teoria implícita. Ambos têm legitimidade para fazer isso" (p. 110).

Parece-nos que "organizar" esse diálogo, de modo a que não se fortaleça a dicotomia teoria-prática ou que não falemos apenas endogenamente, surge como um caminho para reduzir o hiato universidade-escola e para admitirmos as inter-relações entre os saberes e os fazeres desses docentes, em seus diferentes níveis, a partir da possibilidade de reconhecermos também as escolas - uma vez que Ihes sejam conferidas as condições adequadas - como espaços institucionais de crítica, de pesquisa e de construção do conhecimento, em trabalho colaborativo e não dependente do ambiente universitário.

Kleiman (2001), discutindo a formação do professor de língua portuguesa, destaca a necessidade de buscar a ampliação do letramento desses docentes, familiarizando-os com os discursos e as práticas de leitura e de escrita de prestígio e entendendo-as como "uma parte integral da identidade profissional docente" (p. 39). Em nossos dados, além da aproximação com o arcabouço teórico, registramos as menções de todos os professores pesquisadores quanto à participação frequente, nos últimos cinco anos, em eventos científicos com apresentação dos resultados de suas investigações e em bancas avaliadoras, bem como menções à própria produção de relatórios e artigos científicos, submetidos ao crivo de pareceristas. Uma parte importante do letramento acadêmico constitui-se, portanto, nessa atuação junto aos pares.

Motta-Roth (2013) conceitua o letramento acadêmico como um processo pertinente ao contexto de ensino e pesquisa na universidade, "envolvendo a aprendizagem do modo de pensar, atuar e se comunicar em situações de produção de conhecimento científico em áreas específicas" (p. 143). Cadilhe e Garcia-Reis (2017) acrescentam que tal conceituação inclui "práticas de leituras e estudos de artigos, verbetes científicos, relatórios, resenhas, bem como a produção desses mesmos gêneros, como modo de engajar-se na produção de conhecimento" (p. 225). Dessa forma, considerando as ações e os afazeres implicados nas práticas investigativas de nossos professores pesquisadores, somados às demais experiências vivenciadas no interior da instituição pesquisada, pode-se supor que há, para e pela pesquisa, uma ampliação no letramento acadêmico desses docentes.

Para a efetivação da atividade de pesquisa, segundo nossos docentes, ora se parte das experiências vivenciadas no ambiente escolar, na sala de aula e no trato com o objeto de 
ensino, ora se buscam na teoria já consolidada bases para travar diálogo e relações com o trabalho e a postura docente. Essa circularidade, que imageticamente representa uma espécie de retroalimentação da pesquisa com e pelo trabalho de ensino e deste com e por aquela, parece poder representar muitas das colocações de nossos entrevistados, que não veem esse movimento como um circuito fechado, mas como uma dinâmica multidirecional.

\section{A pesquisa e a autonomia docente}

Podemos constatar, na fala de nossos sujeitos, o entendimento das práticas investigativas como um recurso de desenvolvimento profissional, capaz de desautomatizar, de dar ânimo para manter-se em formação e em novas pesquisas, e de valorizar a própria profissão, como é o caso da fala da docente $\mathrm{R}_{5}$, para quem a pesquisa a mantém "estimulada", e de outros professores, como se pode ver nos trechos abaixo:

Toda a minha formação, desde a graduação até agora, foi pontuada pela pesquisa (...). A minha formação como docente sempre esteve muito fundamentada nessa trajetória de pesquisadora. Foi sempre um diálogo intenso... me abriu muitos horizontes, me trouxe muitas leituras, fez eu me apropriar da ideia de que eu tenho sempre que estar atrás de novos conhecimentos - não só aquele que está previsto na ementa, no curso, mas aquilo que te instiga a ir atrás de conhecimento novo. [R1]

Eu acho que fazer pesquisa mostra que o profissional, em âmbitos acadêmicos, ele quer um pouco mais, indo além, como se o profissional quisesse se manter atualizado, né, não se manter acomodado (...). Quando eu me mantenho estudando, me mantenho pesquisando ou criando novas formas de pesquisa, eu mantenho a minha mente também trabalhando, porque eu acho que se eu ficasse somente em sala de aula, talvez eu me acomodasse muito. [C2]

A professora pesquisadora R1 afirma, ainda, reconhecer, em si mesma, dadas as ações de pesquisa vivenciadas em sua trajetória, um "espírito pesquisador", o que nos remete ao termo "postura de investigador", utilizado por Soares (2001). Essa docente diz ainda que estimula seus estudantes a desenvolverem o mesmo:

Eu acho que eles têm de sentir esse gostinho de ter uma pergunta, ter uma questão, identificar um problema e que abordagem pode dar a essa situação, como é que vai desfazer esse nó - seja ele o que quer que seja, mas que ele tenha essa... que ele conheça o caminho, né, o caminho de pesquisar sobre um problema que está presente para ele (...) Isso naturalmente vai ser agregado à carreira do indivíduo dali em diante, inclusive se for o caso do

Eutomia, Recife, 27(1): 121-142, Out. 2020 
professor de língua portuguesa do ensino básico. [R1]

A percepção sobre a existência, no exercício de sua profissão, de uma postura investigativa, alicerçada em procedimentos comuns à produção do conhecimento, também foi evidenciada na fala de outros entrevistados:

Eu tenho muito essa ansiedade, essa busca, né... eu estou sempre buscando, através de trabalhos [de pesquisa] que eu faço. A pesquisa formal é muito importante na minha formação, porque ela me mantém lendo o tempo todo. Ela vai matando minha curiosidade o tempo inteiro. $O$ pessoal às vezes me pergunta: 'A Análise Crítica do Discurso não é muito distante do ensino médio?'. E eu respondo: 'É nada!'. Eu acho que a gente precisa ir além. [R3]

Eu tenho uma vontade de continuar pesquisando, de me manter pesquisando, me manter atualizada. A pesquisa contribui muito para a prática pedagógica da gente. Ah, eu posso aplicar teoria semiótica ou fonologia e variação linguistica em sala de aula, claro (...), mas, além disso, é fazer a gente estar em discussão, numa discussão constante, trocando ideias... [R2]

À semelhança dos achados da pesquisa de FALCÃO (2013) junto a professores em atuação na educação básica da Rede Estadual de Pernambuco, houve, também entre os docentes do IFPE, em diferentes momentos, menção à existência de uma postura investigativa e problematizadora, trazida como diferencial por parte desses sujeitos, quando da fala acerca dos impactos formativos oriundos de suas práticas investigativas/científicas, parecendo resultar tais práticas em transformações atitudinais que colaboram para o rompimento de posturas reprodutoras, transmissivas e acríticas por parte desses profissionais.

Coracini (2003), ao tratar do entrecruzamento de diversos discursos que constituem a identidade do professor de língua, diz que "o sujeito-professor se constitui no embate, constante e sem fim, entre o desejo da teoria, lugar da completude, e a prática, lugar da falta, do ilegitimado, do desvalorizado" (p. 207). Para além dessa dicotomia, os registros de "autoridade", de "embasamento" e de "segurança" foram frequentes no discurso de nossos professores pesquisadores. Vejamos:

[Trabalhar com a pesquisa] Dá um respaldo bom, dá mais independência, mais autonomia para a gente. A gente começa a entrar num processo criativo, né, num processo de reprodução menor do que a gente já tem, né, em um processo mais... um processo autoral. [R3]

Eutomia, Recife, 27(1): 121-142, Out. 2020 
Eu acho que a gente passa a ter mais autoridade para falar do assunto. Eu me sinto mais seguro porque tenho mais autoridade, porque eu me respaldo em coisas que eu estou lá trabalhando, em teorias, e aí eu tenho como provar, digamos assim, aquilo, através do próprio material produzido por meio das minhas pesquisas. [C2]

Erickson (1989) estima que a prática de pesquisa é decisiva para o desenvolvimento profissional, na medida em que pode ajudar o professor da educação básica a conquistar sua autonomia, a sair da situação de dependência, quase de imaturidade, em relação aos professores do ensino superior. As falas de $R_{3}$ e $C_{2}$, acima, podem ser vistas como uma materialização desse princípio, na medida em que esses docentes reconhecem que a prática de pesquisa Ihes confere legitimidade para pensar e agir com autonomia no contexto da profissão, do ensino e do ambiente escolar.

Sabemos que, como defende Imbernón (2016), a profissão docente se move num delicado equilíbrio entre as tarefas profissionais e a estrutura de participação social. Parecenos, então, indispensável discutir possibilidades formativas que ampliem a capacidade desses sujeitos de se reinventarem e de compreenderem as mudanças e as incertezas que se lhes apresentam por meio de práticas e experiências de busca, construção, reconstrução e difusão de saberes e conhecimentos.

Por isso, estamos de acordo com Santos (2014), quando esta sugere que a formação dos professores de língua esteja atrelada à pesquisa crítica, de modo a contribuir para o posicionamento desses profissionais face às exigências de seu tempo. Para tanto, é importante que os professores possam mobilizar um conjunto diversificado de saberes que Ihes deem condições de superar noções "cristalizadas" (p. 29) acerca do currículo, das práticas educativas e de linguagem, e dos conhecimentos envolvidos em sua atuação profissional. Sobre isso, vejamos o exemplo dado por R1:

(...) Eu acho que tudo que eu estudei, que li, que escrevi, pesquisei sobre análise linguística [em uma abordagem discursiva], eu não consigo mais estudar substantivo próprio-comum, concreto-abstrato, simples-composto... beleza, vamos pra adjetivo: locução adjetiva é formada assim, beleza, né, vamos para numeral... E assim sucessivamente... Não faz mais sentido pra mim! Acho que esse é um exemplo de como a pesquisa mudou a minha forma de trabalhar conteúdos. [R1]

A adoção de uma lógica formativa pautada no professor como sujeito de conhecimento e de sua prática, e, portanto, legitimamente capaz de produzir e fazer Eutomia, Recife, 27(1): 121-142, Out. 2020 
circular saberes e conhecimentos, permite-lhe romper, como se pode ver na fala de $\mathrm{R} \mathbf{1}$, com dicotomias entre conteúdo e método, saber e experiência, conhecimento e prática, estimulando atitudes e dispositivos formativos que levem a articular "mudanças organizativas e mudanças subjetivas que permitam a construção de nova identidade e cultura profissional" (FREITAS, 2005, p. 45).

Ao definir a formação para além da tradição transmissiva, técnico-reprodutora, Freitas (2005) diz que "formar(-se) profissionalmente implica tomar consciência da experiência de onde cada um de nós retira lições e aprende coisas; consciência que emerge referenciada em pessoas, grupos, situações e acontecimentos que fazem parte de nosso percurso de vida pessoal e profissional." (p. 38). Para o autor, o saber experiencial é um saber "encarnado naquilo que fazemos e naquilo que somos" (p. 48); posição semelhante foi encontrada nas falas de nossos entrevistados acerca da "postura" investigativa construída pela vivência de experiências de pesquisa.

Ter acesso às narrativas de nossos professores pesquisadores acerca de suas trajetórias e práticas investigativas nos faz considerar a pesquisa como um caminho formativo alinhado a essa perspectiva, como uma experiência, tal como concebida por Larrosa (2002), para quem as experiências são (trans)formadoras dos sujeitos, aquilo que "nos passa, o que nos acontece, o que nos toca" (p. 21). Com efeito, as vivências de pesquisa desses docentes nos dizem da capacidade, portanto, da potencialidade, dessa prática de configurar-se como experiência, no sentido transformador, para esses profissionais.

Nossos dados ainda ratificam a atualidade do pensamento da renomada estudiosa e referência da Linguística Aplicada no Brasil, Profa. Celani, a qual escreveu, no prefácio à coleção Faces da Linguística Aplicada - Questões de Método e de Linguagem na Formação Docente (MAGALHÃES; FIDALGO, 2011), que o professor precisa ser "um profissional preparado científica, técnica, tecnológica, pedagógica, cultural e humanamente" (p. 46). Para a autora, com a qual concordamos, a própria pesquisa deve ser entendida como elemento constitutivo do processo de formação, tendo em vista que as experiências investigativas dos professores pesquisadores, traduzidas a partir de suas narrativas, revelam-nos o seu potencial de incrementar o desenvolvimento profissional.

\section{Conclusões}


Conforme já dito, não é apenas como acontecimento cognitivo que a pesquisa pode contribuir no desenvolvimento profissional, já que auxilia na construção e na aquisição de novos saberes por parte do pesquisador, mas também, e sobretudo, como acontecimento social (LÜDKE, 2001). Para os professores pesquisadores deste estudo, a pesquisa dialoga constantemente com as atividades de ensino, muitas vezes em um processo de retroalimentação, chegando a ser compreendida como parte imanente da sua identidade profissional, dispositivo formativo e elemento de reconhecimento e valorização.

A contribuição advinda das leituras feitas e do arcabouço teórico dominado por esses docentes, bem como a familiaridade que eles demonstram com os processos de produção do conhecimento, a ampliação do nível de letramento acadêmico e a oportunidade de interagir e de aprender com os pares foram alguns dos achados de nossa investigação acerca dos elementos formativos relacionados à atividade investigativa.

A pesquisa mostrou-se como princípio formativo, também, ao ser apontada por nossos sujeitos como caminho de desenvolvimento profissional. Ratificando autores como Schnetzler (1998), Soares $(2001 ;$ 2002) e Pimenta (2012), os professores apontam as contribuições das experiências investigativas vivenciadas tanto na formação inicial, como na continuada; no caso desta última, além dos cursos de pós-graduação stricto sensu, foram citados os projetos empreendidos no próprio ambiente de trabalho.

Reconhecemos a existência de limites da atividade de pesquisa no oferecimento de respostas suficientes para os inúmeros desafios do fazer docente, bem como sua estreita dependência das condições de formação e de trabalho, que nem sempre são favoráveis, mas salientamos o valor das práticas investigativas no sentido de possibilitar ao professor o entendimento do processo de produção do conhecimento como caminho para sua formação e atuação profissionais.

Tal dispositivo, como vimos, tem o potencial de contribuir, sobremaneira, para a legitimação e o reconhecimento docentes, na medida em que confere maior segurança e autonomia na elaboração, definição e reinterpretação dos conhecimentos, dos currículos e das práticas escolares desenvolvidas por esses profissionais.

\section{Referências}

ALTMAN, C. A pesquisa linguística no Brasil (1968-1988). São Paulo: Humanitas, 1998. 
ANDRÉ, M. Pesquisa, formação e prática docente. In: ANDRÉ, M. (org.). O papel da pesquisa na formação e na prática dos professores. Campinas: Papirus, 2001, p. 55-70.

ANTUNES, I. Muito além da gramática: por um ensino de línguas sem pedras no caminho. São Paulo: Parábola Editorial, 2007.

BEILLEROT, J. A "pesquisa": esboço de uma análise. In: ANDRÉ, M. (org.). O papel da pesquisa na formação e na prática dos professores. Campinas: Papirus, 2001, p. 71-90.

BRASIL. Conselho Nacional De Educação. Resolução CNE/CP n. 02/2015, de $1^{\circ}$ de julho de 2015. Define as Diretrizes Curriculares Nacionais para a formação inicial em nível superior (cursos de licenciatura, cursos de formação pedagógica para graduados e cursos de segunda licenciatura) e para a formação continuada. Diário Oficial da União: seção 1, Poder Executivo, Brasília, DF, 02 jul. p. 08-12, 2015.

BRASIL. Lei no. 11.892, de 29 de dezembro de 2008. Institui a Rede Federal de Educação Profissional, Científica e Tecnológica, cria os Institutos Federais de Educação, Ciência e Tecnologia, e dá outras providências. Diário Oficial da União: seção 1, p. 1, 30 dez. 2008.

BOURDIEU, P. La práctica de la sociología reflexiva (Seminario de Paris). In: BOURDIEU, P.; WACOUANT, L. Una invitación a la sociología reflexiva. Buenos Aires: Siglo XXI, 2005, p.301-358.

CADILHE, A. e GARCIA-REIS, A. Letramentos na formação de professores a partir de uma concepção discursiva da linguagem: reflexões propositivas. In: MAGALHÃES, T.; GARCIAREIS, A. E FERREIRA, H. (org.) Concepção discursiva de linguagem: ensino e formação docente. Campinas: Pontes Editores, 2017, 213-232. .

CHARLOT, B. Formação de professores: a pesquisa e a política educacional. In: PIMENTA, S.; GHEDIN, E. (org.). Professor reflexivo no Brasil: gênese e crítica de um conceito. São Paulo: Cortez, 2012 p. 103-126.

CONTRERAS, J. A autonomia de professores. São Paulo: Cortez, 2002.

CORACINI, M. J. O olhar da ciência e a construção da identidade do professor de língua. In: Coracini, M. J.; BERTOLDO, E. S. (org.). O desejo da teoria e a contingência da prática: discursos sobre e na sala de aula: língua materna e língua estrangeira. Campinas: Mercado das Letras: 2003 , p. 196-210.

DAYRELL, J. T. A escola como espaço sociocultural. In: DAYRELL, J. T. (org.). Múltiplos olhares sobre educação e cultura. Belo Horizonte: UFMG, 1996, p. 136-161.

DANDURAND, P.; OLIVIER, E. Centralidade dos saberes e educação: em direção a novas problemáticas. Educação \& Sociedade, Porto Alegre, n. 46, p. 380-405, dez. 1993.

DEMO, P. Pesquisa: princípio científico e educativo. São Paulo: Cortez, 1990.

Eutomia, Recife, 27(1): 121-142, Out. 2020 
DE PIETRI, E. A constituição do discurso da mudança no ensino de língua materna no Brasil. 2003. 202 f. Tese (Doutorado em Linguística Aplicada) - Universidade Estadual de Campinas, Instituto de Estudos da Linguagem, São Paulo, 2003.

DINIZ-PEREIRA, J. A pesquisa dos educadores como estratégia para construção de modelos críticos de formação docente. In: DINIZ-PEREIRA, J.; ZEICHNER, K. (org.). A pesquisa na formação e no trabalho docente. Belo Horizonte: Autêntica Editora, 2011, p. 11-38.

DORNELLES, C. A gente não quer ser tradicional, mas... como é que faz daí? Conservadorismo e inovação na formação de professores de português como língua materna. In: SIGNORINI, I. Significados da inovação no ensino de língua portuguesa e na formação de professores. Campinas: Mercado de Letras, 2007, p. 111-146.

ERICKSON, F. Métodos cualitativos de Investigación sobre la Enseñanza. In: WITTROCK, M. La investigación de la enseñanza, II: métodos cualitativos e de observación. Barcelona: Paidós Educador, MEC, 1989, p. 195-301.

FALCÃO, G. L. O professor pesquisador em Pernambuco: concepções e experiências de professores de português das escolas de referência em ensino médio. 2013. Dissertação (Mestrado em Educação) - Centro de Educação, Universidade Federal de Pernambuco, Recife, 2013.

FARE, M.; CARVALHO, I.; PEREIRA, M. Ética e pesquisa em Educação: entre a regulação e a potencialidade reflexiva da formação. Educação, Porto Alegre, v. 40, n. 2, p. 192-202, maio/ago. 2017.

FREIRE, P. Pedagogia do oprimido. 17 ed. Rio de Janeiro: Paz e Terra; 1987.

FREITAS, A. A questão da experiência na formação profissional dos professores. In: FERREIRA, A. T. B; ALBUQUERQUE, E. B. C. de; LEAL, T. F. (org.). Formação continuada de professores: questões para reflexão. Belo Horizonte: Autêntica, 2005, p. 33-50.

IMBERNÓN, F. Qualidade do ensino e formação do professorado: uma mudança necessária. São Paulo: Cortez, 2016.

LÜDKE, M. O professor e a pesquisa. Campinas: Papirus, 2001.

LÜDKE, M.; CRUZ, G. Aproximando universidade e escola de educação básica pela pesquisa. Cadernos de pesquisa, São Paulo, Fundação Carlos Chagas, v. 35, n.135, p.81-109, mai./ago. 2005 .

LÜDKE, M.; RODRIGUES, P. A. M.; PORTELLA, V. C. M. O mestrado como via de formação de professores da educação básica para a pesquisa. Revista Brasileira de Pós-Graduação, V. 9, n. 16, p. 59-83, 2012.

KLEIMAN, A. Letramento e formação do professor: quais as práticas e exigências no local de Eutomia, Recife, 27(1): 121-142, Out. 2020 
trabalho? In: KLEIMAN. A. (org.) A formação do professor: perspectivas da Linguística Aplicada. Campinas: Mercado das Letras, 2001, p. 39-68

LARROSA, J. Notas sobre a experiência e o saber da experiência. Revista Brasileira de Educação, n. 19. p. 20-29, 2002.

MAGALHÃES, M. C.; FIDALGO, S. Questões de método e de linguagem na formação docente. Mercado das Letras: Campinas, 2011.

MOTTA-ROTH, D. Desenvolvimento do Letramento Acadêmico por engajamento em práticas sociais na universidade. In: VIAN Jr., O. e CALBATIANO, C. Língua(gem) e suas múltiplas faces. Campinas: Mercado das Letras, 2013, p. 31-43.

PIMENTA, S. Professor reflexivo: construindo uma crítica. In: PIMENTA, S. G.; GHEDIN, E. (org.). Professor reflexivo no Brasil: gênese e crítica de um conceito. São Paulo: Cortez, 2012, p. 20-62.

SANTOS, L. Dilemas e perspectivas na relação entre ensino e pesquisa. In: ANDRÉ, M. (org.). O papel da pesquisa na formação e na prática dos professores. Campinas: Papirus, 2001, p. 11-26.

SCHNETZLER, R. Prefácio. In: GERALDI, C. M. G. et al. (org.). Cartografias do trabalho docente. Professor(a) pesquisador(a). Campinas: Mercado de Letras: ALB, 1998. p. 07-09.

SOARES, M. As pesquisas nas áreas específicas influenciando o curso de formação de professores. In: ANDRÉ, M. (org.). O papel da pesquisa na formação e na prática dos professores. Campinas: Papirus, 2001, p. 91-106.

SOARES, M. Linguagem e escola: uma perspectiva social. 17. ed. São Paulo: Ed. Ática, 2002.

SUASSUNA, L. Ensaios de pedagogia da língua portuguesa. Recife: EDUFPE, 2006.

TARDIF, M. Saberes docentes e formação profissional. 12. ed. Petrópolis: Vozes, 2011.

TARDIF, M.; LESSARD, C.; GAUTHIER, C. Formação dos professores e contextos sociais. Porto: Rés, 2001.

TARDIF, M.; MOSCOSO, J. A noção de "profissional reflexivo" na educação: atualidade, usos e limites. Cadernos de pesquisa, v. 48, n. 168, p. 388-411, abr./jun. 2018.

\footnotetext{
' Doutora em Educação pela Universidade Federal de Pernambuco. Professora de Língua Portuguesa do Instituto Federal de Educação, Ciência e Tecnologia de Pernambuco - IFPE.

E-mail: gabi.lins.falcao@gmail.com

ii Doutora em Linguística pela Universidade Estadual de Campinas. Professora associada da Universidade Federal de Pernambuco - Centro de Educação - Departamento de Métodos e Técnicas de Ensino e Programa de Pós-graduação em Educação.

E-mail: liviasuassuna6o@gmail.com
} 